\title{
Devemos Incentivar o Ócio ou a Produtividade?
}

\author{
J. DE NAZARÉ T. DIAS
}

\section{RETRIBUiÇÃo E ESTÍMULO AO RENDIMENTO NO TRABALHO}

\begin{abstract}
propósito que domina tôda a política de remuneração é o de retribuir c trabaiho de acôrdo com a importância das atribuições, dificuldades e responsabilidades que the são inerentes. Atribui-se a cada cargo ou emprêgo um salário, cujo valor aumenta à medida que o empregado percorre a estrutura hierárquica e alcança, gradativamente, seus diversos escalões. Procura-se, além đisso, estimular a dedicação ao trabalho e a eficiência no desempenho das funções através de aumentos periódicos, concedidos enquanto o empregado permanece em determinado cargo, procurando-se, por tal forma, recompensar a experiência adquirida no desempenho de funções do mesmo nível. Outras medidas de caráter eminentemente positivo e que se traduzem em vantagem financeira ou de outra índole são postas em prática com o mesmo objetivo. Mas há também providências que sem embargo de sua natureza negativa, visam, por igual, ao maior rendimento do servidor e, conseqüentemente, dos serviços que compete à administração pública prestar e prover. Referimo-nos às deduções salariais decorrentes da falta de assiduidade ou de impontualidade. Busca-se, outrossim fixar linhas de promoção, incrementar o preparo do funcicnário para o exercício de cargos de maior responsabilidade e relêvo, bem como criar ambientes de trabalho e incentivos que aumentem a produtividade da mão de obra. A disposição harmônica de elementos dessa natureza caracteriza o que se pode, com propriedade, denominar de boa política de administração de pessoal.
\end{abstract}

\section{A PASSAGEM PARA A INATIVIDADE}

Ao cessar o exercício do funcionário em proveito da administração pública, procura-se ampará-lo na inatividade por meio do instituto da aposentadoria, seja como decorrência natural de contribuições feitas durante a atividade, para fins de previdência social, ou sob a forma de ônus atribuído ao empregador, independentemente de contribuição do empregado. Os empregados privados subordinam-se ao primeiro daqueles regimes, através das entidades de previdência social; os funcionários públicos enquadram-se no segundo dos citados regimes, cabendo ao Estado arcar com o ônus de suas aposentações. 
O instituto da aposentadoria deve preocupar-se em manter , na inativiciade, situação econômica que permita ao funcionário viver com dignidade, sem distanciar-se do padrão de vida a que se acostumara. Essa preocupação não pode, porém, deixar de levar em conta que a inatividade acarreta, necesràriamente, redução de certos gastos, inevitáveis enquanto o funcionário se acha no pleno desempenho de suas funções. $O$ orçamento mensal do inativo é beneficamente atingido pela redução de dispêndios de transporte, vestuário e alimentação. Os próprios itens orçamentários referentes à habitação e à alimentação são suscetíveis de redução, por vêzes sensíveis, pois o aposentado pode procurar viver em bairros ou outras cidades de vida mais barata. Os encargos de família estão, em geral, reduzidos à época da aposentadoria . O funcionário que se aposenta a pedido, com 35 anos de serviço e que haja ingressado na administração aos vinte anos de idade, terá 55 anos à épơca da aposentação, quando, normalmente, terá concluídas suas responsabilidades pela educação secundária dos filhos, achando-se êstes, portanto, em condições de se dedicarem a ocupação útil que thes assegure a própria subsistência.

Por isso mesmo as vantagens da aposentadoria correspondem, em geral, a uma parte dos vencimentos da atividade e, no máximo, à totalidade dos mesmos.

\section{PRECEITOS CONSTITUCIONAIS QUE TÊM CUIDADO DO ASSUNTO}

A Constituição de 1934, ao dedicar todo um capítulo aos Funcionários Públicos, procurou tornar claro êsse princípio tão necessário, quanto salutar. Depois de enumerar as diversas hipóteses de aposentação e as vantagens correspondentes, fixou a Constituição de 1934 , de modo explícito, a seguinte regra:

"Os proventos da aposentadoria ou jubilação não poderão exceder os vencimentos da atividade" (art. 170, item 7.:).

A Constituição de 1937 foi mais enfática:

"As vantagens da inatividade não poderão, em caso algum, exceder as da atividade" (art. 156, letra $h$ ).

A Constituição de 1946 não reproduziu, infelizmente, regra taxativa do mesmo teor. Tal regra, no entanto, é perfeitamente dispensável, servindo apenas para enfatizar o que decorre de outros preceitos constitucionais e para alertar os legisladores quanto aos abusos que, nesse particular, procuram sempre acobertar-se no manto protetor das leis de favor ou despidas de respeito iritransigente ao interêsse público. Na verdade, se a Constituição estabelece várias regras quanto aos proventos da inatividade, subordinando-as, inflexivelmente, à norma de que são êles integrais se o funcionário contar trinta anos de serviço (art. 191, $\S 2 .^{\circ}$ ), insistindo logo adiante, na integralidade dos proventos quando a invalidez decorrer de acidente no serviço, moléstia profissional ou doença grave contagiosa ou incurável especificada em lei (art. 191. $\S 3 .^{\circ}$ ), não resta a menor dúvida de que o princípio de não poder a aposentadoria determinar vencimentos mais elevados do que os da atividade permanece em pleno vigor. Êsse princípio domina o nosso sistema de aposentação, 
tal como o consagra a Lei Magna, e tem como complemento justo, filiado às circunstâncias e objetivos atrás enunciados, a norma de que

"os proventos da inatividade serão revistos sempre que, por motivo de alteração do poder aquisitivo da moeda, se modificarem os vencimentos dos funcionários em atividade".

\section{A INATIVIDAdE NÃO PODE SER MAIS BEM PAGA DO QUE A ATIVIDADE}

O princípio de que os proventos da inatividade não podem corresponder a vantagens superiores aos vencimentos da atividade se inspira e tem como fundamento razôes de ordem econômica, administrativa e moral.

As razões de ordem econômica foram por nós enunciadas. Do ponto de vista administrativo, cumpre lembrar que a aposentadoria dos servidores do Estado - civis e militares - é custeada pela receita da União, o que importa dizer por tôda a comunidade social que paga impostos. Impõe-se, em vista disso, a maior parcimônia e o maior zêlo na aplicação dos fundos públicos em despesas de caráter não reprodutivo, como é o caso das aposentadorias.

Quanto ao terceiro aspecto, fôrça é reconhecer que, do ponto de vista moral, aquilo que não se pode pagar pelo trabalho não é lícito pagar pelo ćcio, por mais justificáveis ou aparentemente humanitárias que sejam as circunstâncias em que êste é deferido. Política contrária a êsse axioma elementar fere de frente as regras do bom senso e deve ser taxada de contrária à moral, porque imoral é tôda e qualquer prodigalidade com os dinheiros públicos. Além disso, não se compreende a razão de tal política quando se sabe que as classes trabalhadores, que custeiam através dos impostos que pagam a inatividade dos servidores civis e militares, não gozam sequer do benefício da aposentadoria com salário integral.

\section{A LEgislaçÃo POSTERIOR A 1946 TEM SE AFASTAdO DA BOA DOUTRINA E É, INCONSTITUCIONAL}

Apesar das razões que vem de ser expostas, sedimentadas na disciplina jurídica de quase todos os países, a legislação brasileira posterior a 1946 enveredcu por um caminho que não pode deixar de ser taxado de errado, por desrespeitar a Constituição da República e contrariar o bem público e os interêsses da nação.

O ponto de partida foi o Código de Vencimentos e Vantagens dos Militares, cujo mau exemplo foi, em parte, acolhido pelo Estatuto dos Funcionários Civis de 1952 .

Curioso é que o Poder Legislativo, tão sensível à falsa conveniência de acenar com vantagens cada vez maiores e liberalidades pasmosas aos que pretendem ingressar ou já se encontram na inatividade, tem-se mostrado acentuadamente parcimonioso e insensível ao problema de valorização dos ven- 
cimentos dos funcionários que ocupam postos de direção ou chefia e desempenham funções especializadas, desde os operários qualificados até o pessoal de nível técnico, científico ou administrativo especializado. (*)

\section{IMPACTO ORÇAMENTÁRIO}

Esta política estranhamente liberal no trato dos problemas de aposentadoria tem produzido danosos efeitos no Orçamentơ da União.

Levando em conta os números inscritos na proposta orçamentária para 1946, verifica-se que se elevam a Cr\$ 2.303.000.000,00 as dotações destacadas para atender a despesas com inativos e pensionistas civis, sendo $\mathrm{Cr} \$$ 1.412.000.000,00 para inativors e $\mathrm{Cr} \$ 891.000 .000,00$ para pensionistas. As dotações previstas para fazer face a despesas com inativos e pensionistas militares montam a $\mathrm{Cr} \$ 1.983 .487 .000,00$, sendo $\mathrm{Cr} \$ 1.784 .800 .000,00$ para inativos e Cr\$ $198.687 .000,00$ para pensionistas. Em conjunto os encargos sobem a $\mathrm{Cr} \$ 4.286 .487 .000,00$.

Se tomarmos em consideração que as dotações para os servidores civis e militares somam a, aproximadamente, $\mathrm{Cr} \$ 14.000 .000 .000,00$ anuais, verificaremos a porcentagem alarmante - 36\% - que já atingem os encargos da inatividade em relação aos da atividade.

O impacto orçamentário é. portanto, apreciável e tende a agravar-se, se novos rumos não forem, de imediato, traçados para orientar tão série prơblema.

\section{CONCLUSÕES}

Somos um país novo. Apesar da nossa mocidade como nação, estamos adotando práticas de que sequer cogitam os países de civilização adiantada, as nações envelhecidas pela experiência. Vivemos em regime de restrições financeiras, mas adotamos, paradoxalmente, liberalidades que nenhum benefício trazem para o serviço público e para o povo.

Dispondo de um serviço público notòriamente deficiente e mal estruturado, insistimos em adotar medidas legislativas que primam por estimular o ócio, em lugar de incentivar a atividade, como exige e impõe o bom e econômico funcionamento da administração pública.

Algumas vozes já se fizeram ouvir no Parlamento, sem eco, infelizmente. E um eminente Ministro do Supremo Tribunal Federal afirmava, recentemente, com a voz de sua autoridade, que um dos grandes males do Brasil, "que não me canso de apontar, está no quase sistemático estímulo à inativi-

(*) Não podemos considerar como boa solução legislativa o famoso projeto $n^{\circ} 1.082$, que nivelava um funcionário técnico saído da Universidade a um especialista com anos de experiência profissional, estabelecendo uma "horizontalidade" para os empregos públicos contrária aos mais comezinhos princípios de administração de pessoal, aceitos e reconhecidos no mundo inteiro e no próprio país. 
dade de pessoas em pleno vigor à custa do Tesouro Nacional, e inatividade mais remunerada do que a própria atividade".

\section{SUMMARY}

We are a new country. We have been adopting, however, in spite of our green years as a nation, practices that hichly civilized countries have not even taken into consideration, although being nations matured through experience. We live in a regime of financial restrictions. Yet, paradoxically, we allow ourselves liberalities from which no benefit is derived to both public administration and the people.

With a civil service notoriously deficient and poorly organized, we insist on the adoption of legislative measures that primarily aim at stimulating leisure instead of giving incentive to the activity required and imposed by a sound and economic operation of public administration.

A number of protests have been voiced in the Parliament, unfortunately without any consequences. A prominent Justice of the Federal Supreme Court has recently declared. backed by his authority, that one of the Greatest evils of Brazil, "which I never fail to point out, lies in the almost systematic stimulation of people in their full vigour towards inacti. vity at the expense of the National Treasury, inactivity batter paid than activity".

Numerosos indivíduos ainda aproveitáveis têm encontrado nas falhas da nossa legislação o estímulo maior para o esfôrço menor em prol dos superiores interêsses do Estado.

Rubens DA Rocha Paranhos - Assistência Social aos Servidores do Estado - R.S.P., junho de 1950. 